\title{
Diagnosis of Stator Asymmetry in Permanent Magnet Synchronous Motors Using Negative Sequence Current
}

\author{
Akram BENHADJ AMMAR*, Yasser GRITLI, Mohamed BENREJEB \\ Université de Tunis El Manar, Ecole Nationale d'Ingénieurs de Tunis, \\ Laboratoire de Recherche en Automatique (LARA), B.P. 37, 1002 Tunis, Le Belvédère, Tunisia. \\ akram.benhadjammar@enit.rnu.tn (*Corresponding author), \\ yasser.gritli@enit.utm.tn,mohamed.benrejeb@enit.rnu.tn
}

\begin{abstract}
In this paper, a new fault diagnosis approach is developed for stator asymmetry detection and localization in three-phase permanent magnet synchronous motors. Based on spectral analysis, Motor current signature analysis was extensively adopted for stator fault detection, but the same approach fails in identifying the faulty phase which causes the stator asymmetry of the motor. In the present contribution, a new approach is presented for stator fault detection and localization, which is derived from the polar coordinate of the negative-sequence current. A Neuro-fuzzy inference system is adopted for optimizing the fault localization process. The performances of the proposed approach are evaluated by means of numerical simulations, corresponding to a $7.5 \mathrm{~kW}$ three-phase permanent magnet synchronous motor controlled by a conventional field-oriented control scheme.
\end{abstract}

Keywords: Permanent Magnet Synchronous Motor, Fault Diagnosis, Stator fault, Negative Sequence Current, Motor Current Signature Analysis, Adaptive Neuro-fuzzy Inference System.

\section{Nomenclature}

$\begin{array}{ll}L_{q}, L_{d} & q \text { and } d \text { axis inductances. } \\ R^{R} & \text { Resistance of the stator windings. } \\ i_{s a}, i_{s b}, i_{s c} & \text { Stator phase currents. } \\ i_{q}, i_{d} & q \text { and } d \text { axis currents. } \\ v_{q}, v_{d} & q \text { and } d \text { axis voltages. } \\ c_{i}, c_{2}, c_{3} & \text { Switching signals. } \\ \omega_{r} & \text { Angular velocity of the rotor. } \\ \omega_{r e f} & \text { Set-point angular velocity. } \\ f_{e} & \text { Supply frequency. } \\ r_{c} & \text { Fault resistance. } \\ \lambda^{r} & \text { Amplitude of the flux induced by } \\ & \text { permanent magnets of the rotor in the } \\ p_{m} & \text { stator phases. } \\ T_{e} & \text { Number of pole pairs. } \\ F & \text { Electromagnetic torque. } \\ T_{m} & \text { Combined inertia of rotor and load. } \\ \theta & \text { Combined viscous friction of rotor } \\ & \text { and load. } \\ & \text { Rotor angular position. } \\ & \text { Shaft mechanical torque. }\end{array}$

\section{Introduction}

Permanent Magnet Synchronous Motors (PMSMs) have been adopted for a wide variety of industry applications, mainly for their dynamic performances, efficiency, high torque to volume ratio, and high efficiency $[10,32]$. Therefore, diagnosing accurately the source of degradation in this category of machines is a key item, which could not only guarantee safe operation, but reduce significantly expensive unscheduled downtimes leading generally to high costs of maintenance.

Large reliability investigations have revealed that stator faults account for $37 \%$ as source of failures in electrical machines [1]. In fact, stator faults, such as resistance variation, or inter-turn faults, produce a phase asymmetry due to the fact that the phase impedances are no longer equal [9]. Under these conditions, the stator symmetry of the machine is lost, and a reverse rotating magnetic field is produced, leading to additional electromagnetic stress. Furthermore, and as it is stated in $[4,12]$, insulation life is cut in half for every $10{ }^{\circ} \mathrm{C}$ increase, resulting in accelerated aging of the machine. It is obvious that the phase impedances unbalance affects the efficiency of the drive, and leads to unbalanced stator currents and voltages $[12,17]$. The effect of the fault, has been evidenced on different variables of the machine, such as the electromagnetic torque, air-gap flux, or stator phase currents [17, 29-30].

In this context, several diagnostic approaches have been developed for PMSMs under stator asymmetries which can be roughly classified as model-based techniques, signal-based techniques, knowledge-based techniques, and hybrid/active approaches [6, 9, 13-14]. When compared to model-based approaches, signalbased and knowledge-based approaches do not require an accurate model of the machine, nor a 
detailed analysis of the fault mechanism, which is particularly advantageous for online variables monitoring and real time fault tracking [14-16].

According to several recent reviews, signalbased techniques are the preferred approaches for faults diagnosis $[9,14]$. In fact, this interest for signal-based techniques is mainly motivated by the use of accessible signals affected by the stator asymmetry. Considering a large variety of control drives based on PMSMs, the most accessible signals are phase currents and voltages, which makes them the starting point for many diagnostic analysis $[6,9,17]$. More specifically, stator electrical anomalies share the same fault signature, such as stator windings inter-turn shortcircuit, high-resistance connection, or voltage unbalances and they all give rise to a negative sequence that degrades the performances of the machine as quantified in $[12,22]$, considering linefed PMSMs. It is worth noting that this impact is directly dependent on the control schema adopted, which is generally able to compensate the stator asymmetry at its incipient stage as shown in [17, 32]. For a conventional field-oriented controlled PMSMs, signal-based approaches have shown quit interesting results as investigated in $[17,30$, 32]. In [20], the influence of stator asymmetry has been evaluated for a direct torque controlled PMSM drive.

Based on the classical Fast Fourier Transform (FFT), Motor Current Signature Analysis (MCSA) was widely used for stator fault detection with different approaches: analysis of the Park components [11], the use of zero sequence component [18-19, 35], or the use of symmetrical components derived from the space vector theory are used [19, 23, 26]. In [34], the second harmonic of Park current component iq, and speed are used as an assessment of winding fault and as unbalanced voltage source indicator.

Although the good performances of the signal-based techniques, they still vulnerable to the operating point of the machines, or/and unknown combination of electrical and mechanical disturbances.

Modern monitoring and diagnosis techniques dedicated to complex systems [21, 23-24], and specifically for electrical machines [7, 31, 3335], have moved from traditional approaches to advanced ones based on Artificial Intelligence Techniques (AIT). In fact, these techniques require a minimum of intelligent configuration, since no detailed analysis of the fault mechanism is required, nor an advanced machine modelling $[3,5]$. They are devoted to optimal decisionmaking for fault identification and localization issues [28]. In [22], the negative sequence voltage component is used to study the interturns short-circuit fault, the phase-to-ground fault and the phase-to-phase faults for permanent magnets synchronous generator, and to train an Artificial Neural Network (ANN) for automatic fault diagnosis system. The effectiveness of ANN has been evidenced in [28], showing interesting results for the detection of voltage unbalance, independently of the load operating condition.

In this paper, a new fault detection technique is developed for stator asymmetry detection and localization in PMSM controlled by conventional Field-Oriented Control (FOC). The proposed technique is based on the polar coordinate of the negative-sequence current. A Neuro-fuzzy inference system is adopted for optimizing the fault localization process. The main advantages of the developed technique are its simplicity, and robustness against the operating condition for stator fault localization.

This paper is organized as follows. Section 2 presents the control schema adopted for the PMSM under stator asymmetry. A preliminary spectral characterization of the fault, showing the limits of the MCSA in terms of fault localization, is established in Section 3. The proposed approach is fully disclosed, tested, and evaluated in section 4.

\section{Controlled PMSM under stator asymmetry}

\subsection{Controlled PMSM description}

In order to test the performances of the proposed technique, a $7.5 \mathrm{~kW}$ three-phase PMSM model, controlled by a conventional FOC (Figure 1), has been implemented in Matlab/Simulink. The electrical equations of the healthy machine, expressed in the $d-q$ reference frame, are 


$$
\left\{\begin{array}{l}
\frac{d i_{d}}{d t}=\frac{1}{L_{d}} v_{d}-\frac{R}{L_{d}} i_{d}+\frac{L_{q}}{L_{d}} p \omega_{r} i_{q} \\
\frac{d i_{q}}{d t}=\frac{1}{L_{q}} v_{q}-\frac{R}{L_{q}} i_{q}-\frac{L_{d}}{L_{q}} p \omega_{r} i_{d}-\frac{\lambda p \omega_{r}}{L_{q}}
\end{array}\right.
$$

and the corresponding mechanical equations are

$$
\left\{\begin{array}{l}
T_{e}=1.5 p\left[\lambda i_{q}+\left(L_{d}-L_{q}\right) i_{d} i_{q}\right] \\
\frac{d \omega_{r}}{d t}=\frac{1}{J}\left(T_{e}-F \omega_{r}-T_{m}\right) \\
\frac{d \theta}{d t}=\omega_{r}
\end{array}\right.
$$

Assuming a state vector $x=\left[\begin{array}{llll}i_{d} & i_{q} & \omega_{r} & \theta\end{array}\right]^{T}$, an input vector $u=\left[\begin{array}{lll}v_{d} & v_{q} & T_{m}\end{array}\right]^{T}$, and an output vector $y=\left[\begin{array}{ll}i_{d} & i_{q}\end{array}\right]^{T}$, the overall controlled PMSM model, considering (1) and (2), can be rewritten as

$$
\left\{\begin{array}{l}
\dot{x}=A x+B u \\
y=C x
\end{array}\right.
$$

with

$$
\begin{aligned}
& A=\left[\begin{array}{cccc}
-R / L_{d} & L_{q} p \omega_{r} / L_{d} & 0 & 0 \\
-L_{d} p \omega_{r} / L_{q} & -R / L_{q} & -\lambda p / L_{q} & 0 \\
1.5 p i_{q}\left(L_{d}-L_{q}\right) / J & 1.5 p \lambda / J & -F / J & 0 \\
0 & 0 & 1 & 0
\end{array}\right] \\
& B=\left[\begin{array}{cccc}
1 / L_{d} & 0 & 0 & 0 \\
0 & 1 / L_{q} & 0 & 0 \\
0 & 0 & -1 / J & 0
\end{array}\right]^{T}
\end{aligned}
$$

When a FOC is concerned, classically the d-axis component $i_{d r e f}$ is set to zero, leading to the following new formulation of (3)

$$
\left\{\begin{array}{l}
\dot{x}_{s}=A_{s} x_{s}+B_{s} u_{s} \\
y_{s}=C_{s} x_{s}
\end{array}\right.
$$

with

$$
A_{s}=\left[\begin{array}{ccc}
-R / L_{q} & -\lambda p / L_{q} & 0 \\
1.5 p \lambda / J & -F / J & 0 \\
0 & 1 & 0
\end{array}\right]
$$

$$
B_{s}=\left[\begin{array}{ccc}
1 / L_{q} & 0 & 0 \\
0 & -1 / J & 0
\end{array}\right]^{T}
$$

The stator asymmetry was classically emulated by an additional resistance $r c$ inserted in series to a stator phase as illustrated in Figure 1. As it is simulated, the fault can be assumed as a voltage unbalance [26-27]. In fact, the calibration of the fault, and more specifically the value of the additional resistance rc was adjusted according to the IEEE standards definition [8], expressed by

$\left\{\begin{array}{l}m=\left(V_{\text {amax }}+V_{b \max }+V_{c \max }\right) / 3 \\ d_{m}=\max \left(\left|m-V_{\text {amax }}\right|,\left|m-V_{b \max }\right|,\left|m-V_{c \max }\right|\right) \\ P_{v u}=100 \times d_{m} / m\end{array}\right.$

where $m$ is the average voltage peak value. The widest deviation between the phase voltages is denoted by $d_{m}$. Finally, the normalized ratio between $d_{m}$ and $m$, is expressed by $P_{v u}$ in (9).

\subsection{Time domain characterization}

The PMSM has been initially simulated in healthy condition and for the rated operating point. The time domain evolution of the three-phase stator currents is reported in Figure 2-a, showing a clear symmetry of the system. The corresponding signals under stator asymmetry condition are reported in Figure 2-b, where the stator asymmetry

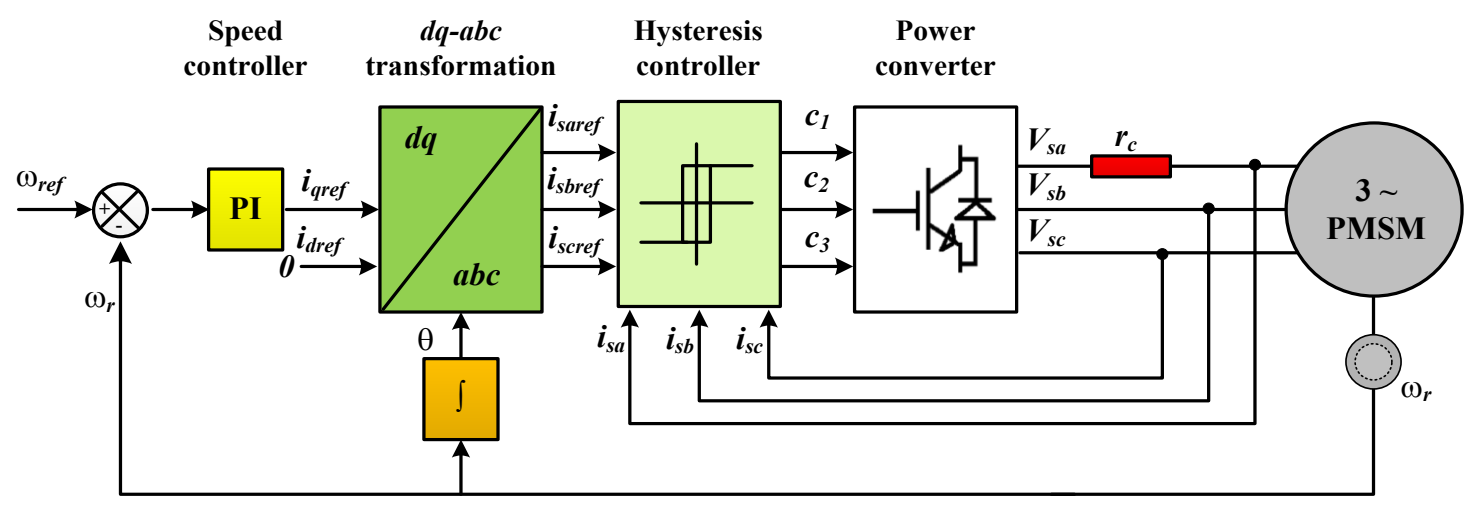

Figure 1. Block scheme of the FOC, with hysteresis current controllers, for a three-phase PMSM 
is clearly evidenced by the unbalance of the threephase currents.

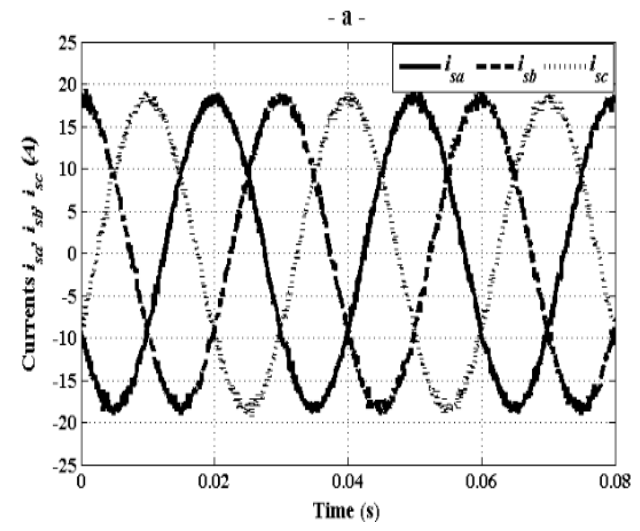

b -

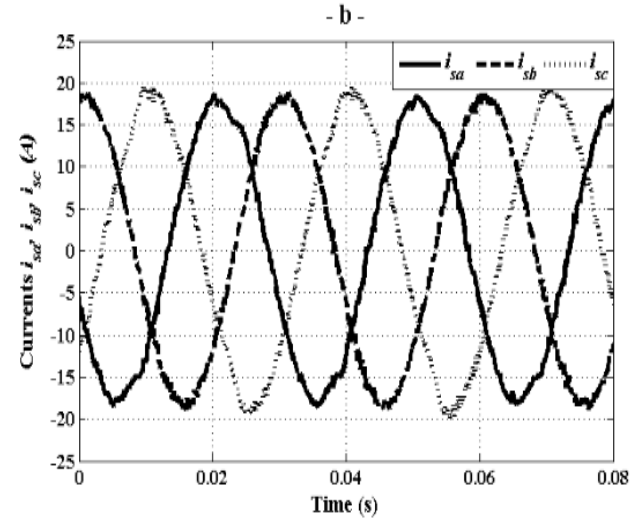

Figure 2. Behaviors of the phase currents, under (a) healthy and (b) faulty conditions

In Figure 3, the behaviors of the currents space vectors, under healthy (Figure 3-a) and stator asymmetry (Figure 3-b) are represented.
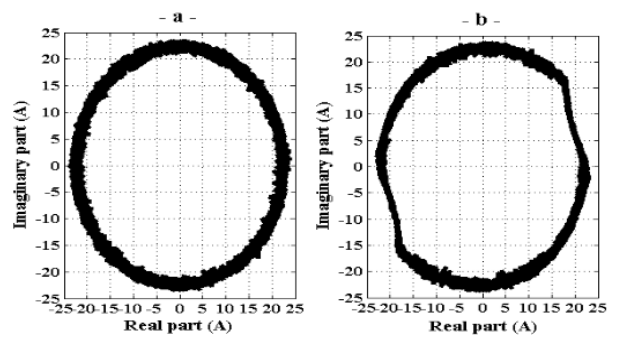

Figure 3. Behaviors of the currents space vector, under (a) healthy and (b) faulty conditions

Under healthy condition, the current space vector shows a perfect circular behavior. On the contrary, under stator asymmetry, a different behavior of the same quantity can be easily evidenced. In the next section, the MCSA based on spectral analysis will be evaluated for different stator asymmetries configurations.

\section{Spectral fault characterization}

In this section, a stator asymmetry fault frequency signature is extracted by spectral analysis. The harmonic spectra are obtained by applying the FFT algorithm to the instantaneous values of the three-phase currents.

The spectra have been normalized setting at 0 $\mathrm{dB}$ the fundamental harmonic component at frequency $f_{e}=33 \mathrm{~Hz}$. For the sake of clarity, only the spectra corresponding to the faulty cases are reported in Figures 4-6.

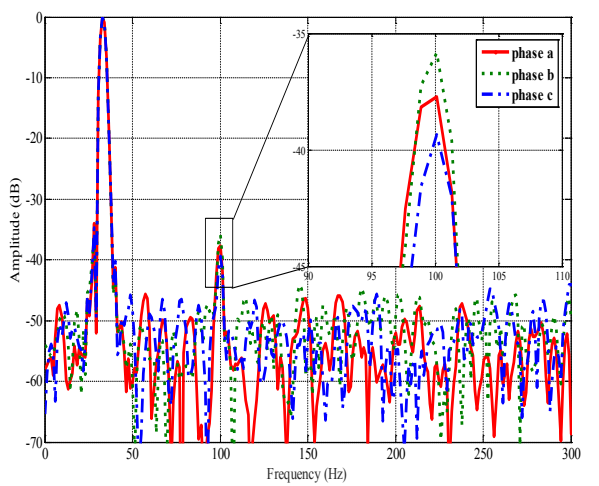

Figure 4. Spectra of the three phase currents under a stator asymmetry caused by phase a

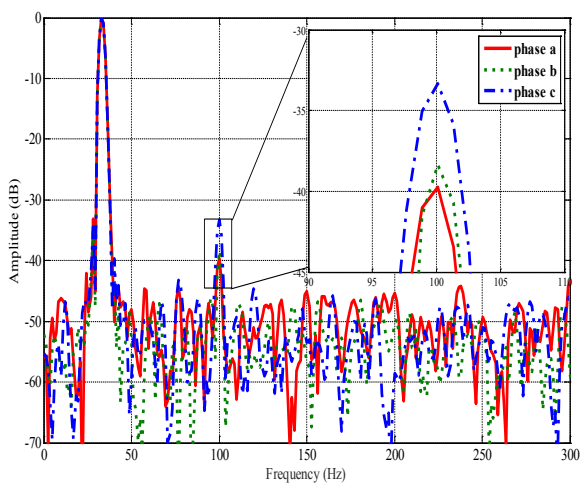

Figure 5. Spectra of the three phase currents under a stator asymmetry caused by phase $b$

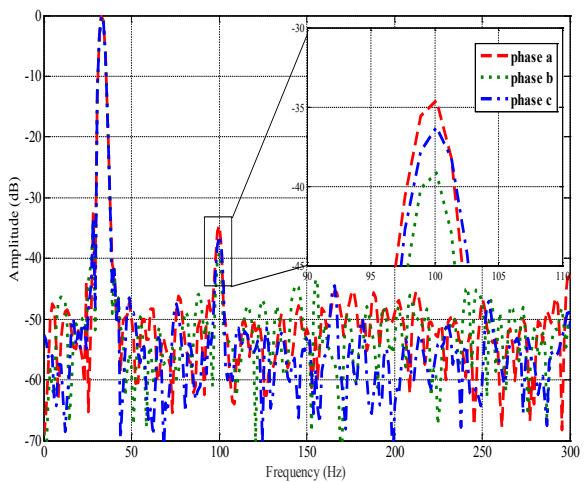

Figure 6. Spectra of the three phase currents under a stator asymmetry caused by phase c 
For reference, all the amplitudes of the harmonics of interest are reported for healthy and faulty cases in Table. 1. It is worth noting that comparing the amplitude variations, from healthy to faulty conditions, of the different harmonics and mainly the $5^{\text {th }}$ harmonic, show a clear detectability of the stator fault. Observing the spectra reported in Figures 4-6, corresponding to different faulty cases, it is evident that the discrimination in amplitude for the $5^{\text {th }}$ harmonic, between the different phases, is under a range of approximately $5 \mathrm{~dB}$. Considering possible effects of noise, local disturbances, or/and processing parameters consideration, can make the process of faulty phase localization practically impossible.

Table 1. Currents harmonics amplitudes in decibels under healthy and stator asymmetries

\begin{tabular}{|l|l|l|l|l|l|l|}
\hline & \multicolumn{2}{|l|}{ Healthy } & \multicolumn{3}{|c|}{ Stator asymmetry } \\
\hline $\begin{array}{l}\text { Harmonics } \\
\text { order }\end{array}$ & $\mathbf{3}^{\text {rd }}$ & $\mathbf{5}^{\text {th }}$ & $7^{\text {th }}$ & $\mathbf{3}^{\text {rd }}$ & $\mathbf{5}^{\text {th }}$ & $7^{\text {th }}$ \\
\hline Phase a & -60 & -58 & -66 & -36 & -35 & -37 \\
\hline Phase b & -65 & -62 & -56 & -41 & -46 & -54 \\
\hline Phase c & -66 & -63 & -55 & -32 & -33 & -36 \\
\hline
\end{tabular}

Finally, at this level of the investigation, the frequency domain analysis, based on the fault signature derived from the different spectra of the stator phase currents, can be considered for fault detection, but fails to identify the phase affected by the fault.

To cope with the above limitation of frequency domain analysis for fault localization, a new approach will be developed and tested in the next sections.

\section{Proposed approach for stator asymmetry detection and localization}

In this section, the main concept of the proposed approach for stator asymmetries detection and localization is fully developed. In fact, it consists of three main steps as illustrated in Figure 7.

\subsection{Definition of the stator fault indicator}

The first step to be carried out is the acquisition of the three-phase currents under stationary condition. Then the signal conditioning step is completed by filtering the three currents, in order to reduce the ripple effect in currents due to the pulse width modulation. The second important step is the cyclic tracking of the maximum phase currents values $\left(I_{s a \text { Max }}, I_{s b \text { Max }}, I_{s c \text { Max }}\right)$, which will be used for calculating the corresponding negative sequence component $I$ given by

$I_{-}=\frac{1}{3}\left[I_{s a_{-} M a x}+\bar{a} \cdot I_{s b_{-} M a x}+a \cdot I_{s c_{-} M a x}\right]$.

where

$a=-0.5+j \frac{\sqrt{3}}{2}$

and $\bar{a}$ is the complex conjugate of $a$. The NSC is used in its polar form, where the NSC scale value represents the amplitude, and the NSC angle value is corresponding to the phase.

The final NSC evaluation stage is based on the interpretation of the NSC polar coordinates in two steps. The first one is dedicated to the stator asymmetry detection, where the NSC amplitude is compared to zero. Since the NSC amplitude can be affected by noise, and/or intrinsic stator asymmetries, it is convenient to consider a security factor $\xi$, slightly greater than zero, in order to avoid false alarms during the detection process.

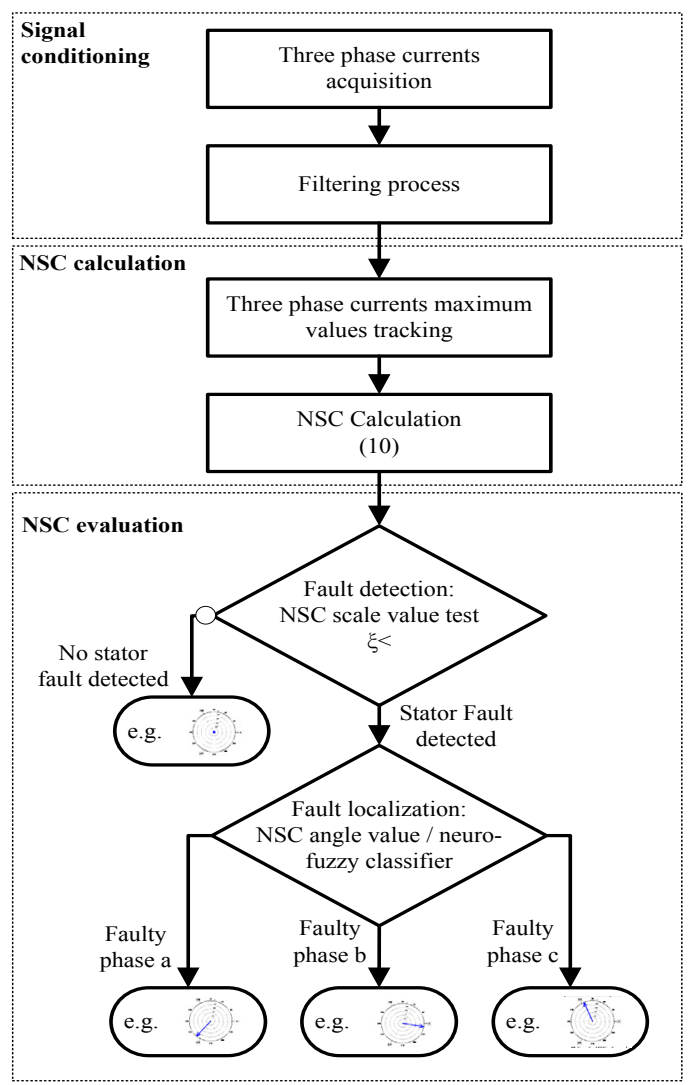

Figure 7. Flowchart of the proposed approach for fault detection and localization based NSC 
Once a stator asymmetry is detected, the second step is the localization of the faulty phase. The process of fault localization is based on the NSC angle, as described by Figure 8. Effectively, depending on the stator phase affected by the fault, the NSC angle orientation changes accordingly (Figure 8), leading to a classification process characterized by the following rules:

- If (NSC angle is in the sector 1) then (Fault location is in the phase a).

- If (NSC angle is in the sector 2) then (Fault location is in the phase b).

- If (NSC angle is in the sector 3) then (Fault location is in the phase c).

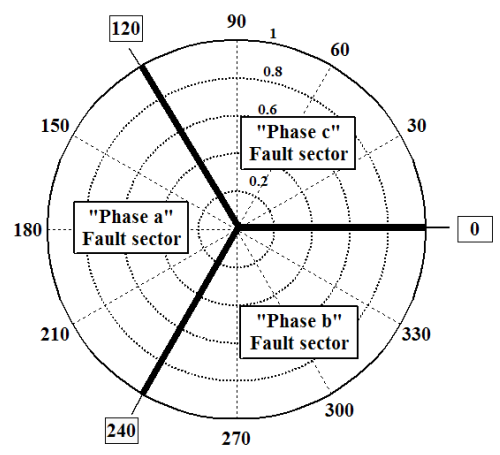

Figure 8. All-or-nothing angles classification scheme for NSC-based fault localization

Effectively, the above approach has been validated successfully tested on the controlled system of Figure 1, under full-load operating condition. The corresponding results are shown in Figures 9-12. Initially, the motor has been tested under healthy condition, leading to a zero value of the NSC in terms of amplitude and phase angle (Figure 9). This fact indicates a reliable diagnosis of healthy condition for the PMSM.

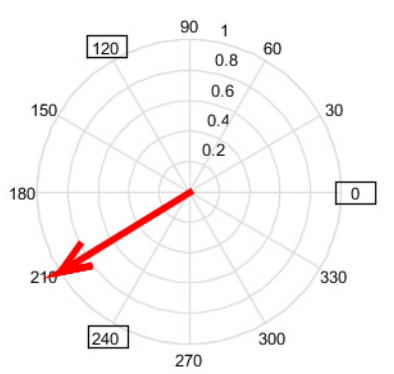

Figure 9. Normalized NSC in the complex plane under healthy stator condition

Then, three different stator asymmetries have been tested to evaluate the ability of the proposed approach, leading to the reported results in Figures
10-12. As can be seen, the fault localization is clearly evidenced for each case, leading to an effective tool for stator asymmetry localization.

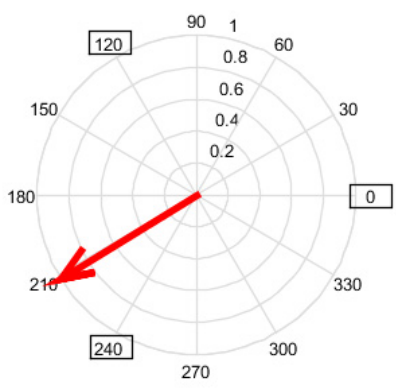

Figure 10. Normalized NSC in the complex plane under stator fault in "phase a"

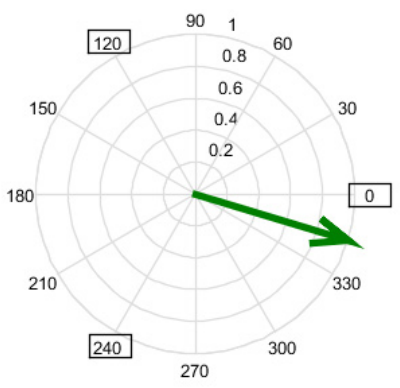

Figure 11. Normalized NSC in the complex plane under stator fault in "phase b"

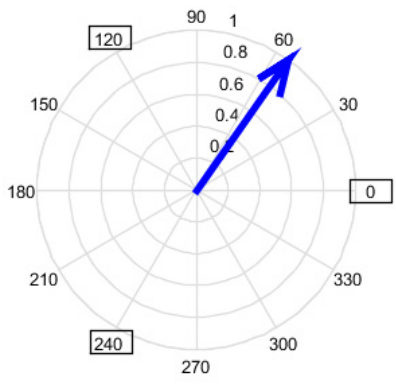

Figure 12. Normalized NSC in the complex plane under stator fault in "phase c"

In order to test the sensitivity of the proposed process for fault localization, several tests under different stator asymmetry configurations, and different speed operating conditions (from 130 $\mathrm{rad} / \mathrm{s}$ to $220 \mathrm{rad} / \mathrm{s}$ ) have been carried out. The corresponding results are reported in Figure 13, where the reliability of the proposed approach is confirmed, but with a little dependency on the speed operating condition, as it is the case of all signal-based techniques [14-15]. In the following subsection, a neuro-fuzzy classifier is introduced to cope with the above limitation. 


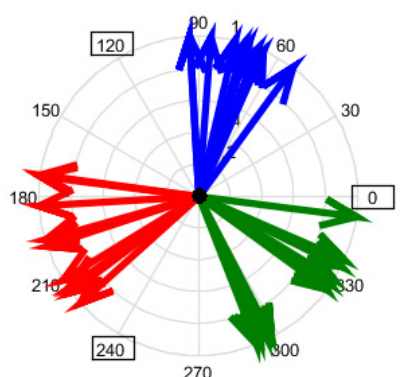

Figure 13. Normalized NSC in the complex plane under different operating speed, and different faulty phase conditions: phase a (Red), phase b (Green), and phase c (Blue)

\subsection{Automatic stator fault diagnosis}

According to the results obtained in Figure 13, the speed operating point affects slightly the NSC angle under the same sector. At this stage, the key point to develop an automatic process for stator fault diagnosis, is to consider the different NSC angles as a database for a neuro-fuzzy classifier and decision making for fault localization. The ANFIS of the adopted artificial neural network structure (Figure 14), using a Takagi-Sugeno fuzzy inference system, is based on 6 layers $[2,25]$.

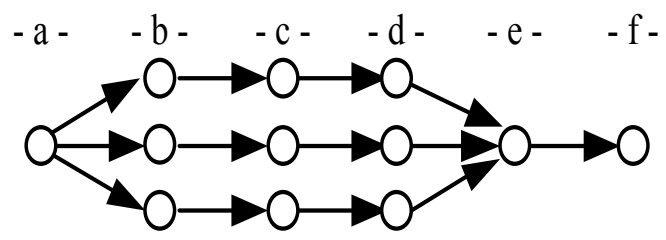

Figure 14. Structure of a neuro-fuzzy model

The first layer (- a -) is the input, the second one $(-b-)$ contains the input membership functions in the form of three fuzzy membership functions. The third layer (- c -) represents the inference rules, which are aforementioned as the classification rules; the fourth layer (- d -) carries the Sugeno output membership functions in the form of fuzzy singletons, the fifth layer (- e -) corresponds to the aggregated output and the sixth (- $f-$ ) contains the decision result output.

Based on the input membership functions of Figure 15 and the inference rules, the ANFIS will considerate the NSC angles database to generate an initial fuzzy inference system, then to train and adapt the parameters to minimize the errors.

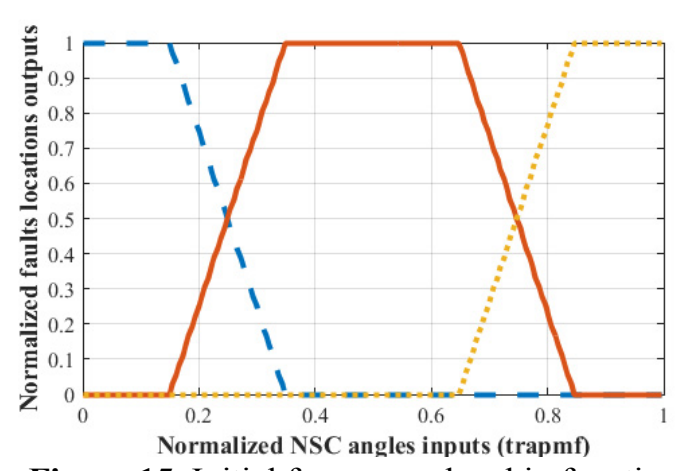

Figure 15. Initial fuzzy membership functions of the NSC angle input variable in the fault localization classifier

The results of the trained ANFIS are shown in Figures 16-18. It is worth noting that the inputoutput data are conventionally normalized between $[0: 1]$ for numerical stability reason.

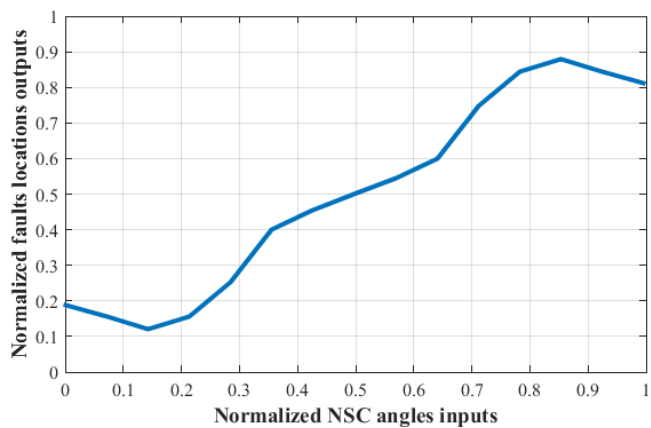

Figure 16. The fault location decision profile of the neuro-fuzzy logic application

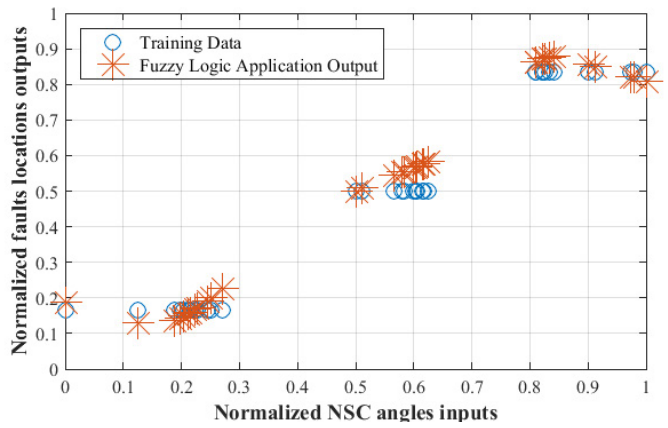

Figure 17. Training data used for identifying parameters of generic neuro-fuzzy model

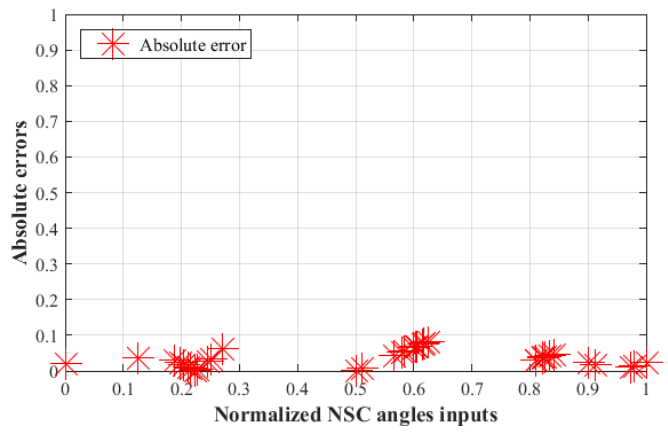

Figure 18. Absolute error between the training data set output and the estimated data by the ANFIS model output 
For the considered single input ANFIS, and after training, the decision profile for fault localization is depicted in Figure 16.

Figure 17 shows a comparison between the desired decision used for the training cycle, and the ANFIS predicted decision results. The corresponding very low absolute errors, reported in Figure 18, are the proof of the procedure effectiveness for stator fault localization.

Considering the obtained results, the proposed approach has shown high efficiency for stator asymmetry detection and localization for the controlled PMSM. Its main advantages are simplicity, reduced latency of processing after the training process, which makes the proposed diagnostic approach practically automatic.

\section{Conclusion}

In this paper, an automatic intelligent technique for the diagnosis of stator asymmetries is proposed. The proposed approach is based on the polar coordinate of the negative-sequence current. The amplitude value is adopted for the fault detection

\section{REFERENCES}

1. Albrecht, P. F., Appiarius, J. C., McCoy, R. M., Owen, E. L. \& Sharma, D. K. (1986). Assessment of the Reliability of Motors in Utility Applications-Updated, IEEE Transactions on Energy conversion, (1), 39-46.

2. Benrejeb, M., Soudani, D., Sakly, A. \& Borne, P. (2006). New Discrete Tanaka Sugeno Kang Fuzzy Systems Characterization and Stability Domain, International Journal of Computers Communications \& Control, 1(4), 9-19.

3. Benrejeb, M. (2010). Stability Study of Two Level Hierarchical Nonlinear Systems. Plenary lecture. In IFAC Proceedings Volumes, 43(8) (pp. 30-41).

4. Bonnett, A. H. \& Yung, C. (2008). Increased Efficiency Versus Increased Reliability, IEEE Industry Applications Magazine, 14(1), 29-36.

5. Borne, P., Benrejeb, M. \& Haggege, J. (2007). Neural Networks. Presentation and Applications (in Frensh: les Réseaux de Neurones. Présentation et Application). Technip Editions. step, and the phase angle is then adopted for the fault localization process. A Neuro-fuzzy inference system is adopted for optimizing the fault localization process.

The performances of the whole proposed process have been validated for a PMSM, controlled by conventional FOC strategy, under different configurations of stator asymmetries. The developed method can be extended to the detection of other types of electrical faults affecting PMSMs.

\section{Appendix}

PMSM parameters

\begin{tabular}{|l|l|}
\hline Rated power & $7.5 \mathrm{~kW}$ \\
\hline Stator phase resistance & $0.129 \Omega$ \\
\hline Armature inductance & $1.53 \mathrm{mH}$ \\
\hline Pole pairs & 2 \\
\hline Moment of inertia & $0.00333 \mathrm{~kg} . \mathrm{m}^{2}$ \\
\hline Flux linkage & $0.1821 \mathrm{~Wb}$ \\
\hline
\end{tabular}

6. Capolino, G. A., Antonino-Daviu, J. A. \& Riera-Guasp, M. (2015). Modern Diagnostics Techniques for Electrical Machines, Power Electronics, and Drives, IEEE Transactions on Industrial Electronics, 62(3), 1738-1745.

7. Chen, C., Zhang, B., Vachtsevanos, G. \& Orchard, M. (2011). Machine Condition Prediction Based on Adaptive Neuro-fuzzy and High-Order Particle Filtering, IEEE Transactions on Industrial Electronics, 58 (9), 4353-4364.

8. Chen, T. H., Yang, C. H. \& Yang, N. C. (2013). Examination of the Definitions of Voltage Unbalance, International Journal of Electrical Power \& Energy Systems, 49(1), 380-385.

9. Cheng, M., Hang, J. \& Zhang, J. (2015). Overview of Fault Diagnosis Theory and Method for Permanent Magnet Machine, Chinese Journal of Electrical Engineering, 1(1), 21-36.

10. Cheng, M. \& Zhu, Y. (2014). The State of the Art of Wind Energy Conversion Systems and Technologies: A review, Energy Conversion and Management, 88, 332-347. 
11. Cruz, S. M. \& Cardoso, A. M. (2001). Stator Winding Fault Diagnosis in Three-Phase Synchronous and Asynchronous Motors, by the Extended Park's Vector Approach, IEEE Transactions on industry applications, 37(5), 1227-1233.

12. Ferreira, F., De Almeida, A. \& Cistelecan, M. (2009). Voltage Unbalance Impact on the Performance of Line-Start PermanentMagnet Synchronous Motors. In Proc. $6^{\text {th }}$ Int. Conf. EEMODS (pp. 123-137).

13. Gandhi, A., Corrigan, T. \& Parsa, L. (2011). Recent Advances in Modeling and Online Detection of Stator Inter-Turn Faults in Electrical Motors, IEEE Transactions on Industrial Electronics, 58(5), 1564-1575.

14. Gao, Z., Cecati, C. \& Ding, S. X. (2015). A Survey of Fault Diagnosis and Fault-Tolerant Techniques - Part I: Fault Diagnosis with Model-Based and Signal-Based Approaches, IEEE Transactions on Industrial Electronics, 62(6), 3757-3767.

15. Gao, Z., Cecati, C. \& Ding, S. X. (2015). A Survey of Fault Diagnosis and Fault-Tolerant Techniques - Part II: Fault Diagnosis with Knowledge-Based and Hybrid/Active Approaches, IEEE Transactions on Industrial Electronics, 62(6), 3768-3774.

16. Gao, Z., Ding, S. X. \& Cecati, C. (2015). Real-Time Fault Diagnosis and FaultTolerant Control, IEEE Transactions on industrial Electronics, 62(6), 3752-3756.

17. Gritli, Y., Tani, A., Rossi, C. \& Casadei, D. (2016). Closed-Loop Control Impact on Condition Monitoring of High-Resistance Connections in PMSM Based on Power Signature Analysis. In IECON $2016-42^{\text {nd }}$ Annual Conference of the IEEE Industrial Electronics Society (pp. 6966-6970).

18. Hang, J., Zhang, J., Cheng, M., Zhang, B. \& Ding, S. (2016). High-Resistance Connection Detection in Permanent Magnet Synchronous Machine Using Zero-Sequence Current Component, IEEE Transactions on Power Electronics, 31(7), 4710-19.

19. Hang, J., Zhang, J., Cheng, M. \& Huang, J. (2015). Online Inter-Turn Fault Diagnosis of Permanent Magnet Synchronous Machine Using Zero Sequence Components, IEEE Transactions on Power Electronics, 30(12), 6731-6741.
20. Haque, M. E. \& Rahman. M. F. (2001). Influence of Stator Resistance Variation on Direct Torque Controlled Interior Permanent Magnet Synchronous Motor Drive Performance and Its Compensation. In Conference Record of the IEEE Industry Applications Conference (pp. 2563-2569).

21. Hernandez, M., Del Muro, B., Cortes, D. \& Sanchez, J. C. (2012). An Easy to Apply Methodology for Fault Detection and Isolation in Linear Systems, Studies in Informatics and Control, 21(3), 275-282.

22. Khader Bouzid, M. B., Champenois, G. Maalaoui, A. \& Tnani, S. (2017). Efficient Simplified Physical Faulty Model of a Permanent Magnet Synchronous Generator Dedicated to the Stator Fault Diagnosis - Part I: Faulty Model Conception, IEEE Transactions on Industry Applications, 53(3), 2752-2761.

23. Lajmi, F., Talmoudi A. J. \& Dhouibi. H. (2017). Fault Diagnosis of Uncertain Systems Based on Interval Fuzzy PETRI Net, Studies in Informatics and Control, 26(2), 239-248.

24. Lajmi, F., Telmoudi, A. J. \& Nabli, L. (2016, April). System Performance Improvement by Dynamic Monitoring. In International Conference on Control, Decision and Information Technologies (CoDIT) (pp. 736-740).

25. Manai, Y. \& Benrejeb, M. (2011). New Condition of Stabilisation for Continuous Takagi-Sugeno Fuzzy System Based on Fuzzy Lyapunov Function, International Journal of Control and Automation, 4(3), 51-63.

26. Mazzoletti, M. A., Bossio, G. R., De Angelo, C. H. \& Espinoza-Trejo, D. R. (2015). A New Strategy for Detection and Isolation of Stator Faults in PMSM. In IEEE 2015 XVI Workshop on Information Processing and Control (pp.1-6).

27. Mazzoletti, M. A., Bossio, G. R., De Angelo, C. H. \& Espinoza-Trejo, D. R. (2017). A Model-Based Strategy for Inter-Turn ShortCircuit Fault Diagnosis in PMSM, IEEE Transactions on Industrial Electronics, 64(9), 7218-28.

28. Moosavi, S. S., Djerdir, A., Ait-Amirat, Y. \& Kkuburi, D. A. (2012). Artificial Neural Networks Based Fault Detection in 3-Phase PMSM Traction Motor. In 2012 
$X X^{\text {th }}$ International Conference on Electrical Machines (pp. 1579-1585).

29. Ortega, A. J. P. \& Xu, L. (2017). Investigation of Effects of Asymmetries on the Performance of Permanent Magnet Synchronous Machines, IEEE Transactions on Energy Conversion, 32(3), 1002-1011.

30. Refaat, S. S., Abu-Rub, H., Mohamed, A. \& Trabelsi, M. (2017). Investigation into the Effect of Unbalanced Supply Voltage on Detection of Stator Winding Turn Fault in PMSM. In Proceedings of the IEEE International Conference on Industrial Technology (pp. 312-317).

31. Rodriguez, N., Lagos, C., Cabrera, E. \& Cañete, L. (2017). Extreme Learning Machine Based on Stationary Wavelet Singular Values for Bearing Failure Diagnosis, Studies in Informatics and Control, 26(3), 287-249.

32. Ruuskanen, V., Immonen, P., Nerg, J. \& Pyrhönen, J. (2012). Determining Electrical
Efficiency of Permanent Magnet Synchronous Machines with Different Control Methods, Electrical Engineering, 94(2), 97-106.

33. Tan, W. W. \& Huo, H. (2005). A Generic Neurofuzzy Model-Based Approach for Detecting Faults in Induction Motors, IEEE Transactions on Industrial Electronics, 52(5), 1420-1427.

34. Urresty, J. C., Riba, J. R., Saavedra, H. \& Romeral, L. (2011). Detection of InterTurns Short Circuits in Permanent Magnet Synchronous Motors Operating under Transient Conditions by Means of the Zero Sequence Voltage. In Proceedings of the $14^{\text {th }}$ European Conference on Power Electronics and Applications (pp. 1-9).

35. Zhang, J., Hang, J., Ding, S. \& Cheng, M. (2017). Online Diagnosis and Localization of High-Resistance Connection in PMSM with Improved Fault Indicator, IEEE Transactions on Power Electronics, 32(5), 3585-3594. 